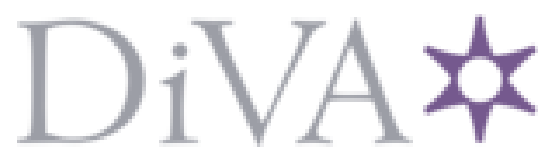

http://www.diva-portal.org

This is the published version of a paper published in Vård $i$ Norden.

Citation for the original published paper (version of record):

Ångström Brännström, C., Dahlqvist, V., Strandberg, G., Norberg, A. (2014)

Descriptions of comfort in the social networks surrounding a dying child.

Vård i Norden, 34(113): 4-8

Access to the published version may require subscription.

N.B. When citing this work, cite the original published paper.

Permanent link to this version:

http://urn.kb.se/resolve?urn=urn:nbn:se:umu:diva-98492 


\title{
Descriptions of comfort in the social networks surrounding a dying child
}

\author{
Charlotte Ångström-Brännström, PhD, Vera Dahlqvist, PhD, Gunilla Strandberg, PhD, Professor and Astrid Norberg, PhD, \\ Professor emerita
}

\begin{abstract}
Aim: The aim of this study was to describe how comforters of one dying child were comforted, described by the child's mother and nurse. Background: The death of a child is one of the greatest losses parents can sustain and a stressful experience for nurses. Those who provide comfort may also need comfort, yet little is known about how comforters are comforted.

Method: The interviews with mother and nurse were analysed using content analysis. Persons and activities mentioned as comforting were outlined in a sociogram.

Findings: The findings show that the mother received comfort from her child and family, the nurse, extended family and others close to the family. She found comfort in being involved in the care and sharing worries with the nurse and in self-comfort. She described that siblings found comfort in each other, in living everyday life, in music and in expressing their feelings in drawings. The nurse gained comfort from sharing hardships with colleagues and a relative and from making a difference to the child.

Conclusion: The findings provide a picture of interacting comforting social networks surrounding one dying child.
\end{abstract}

KEY WORDS: child, comfort, family, palliative care, social network

\section{Background}

The death of a child is considered to be one of the greatest losses a parent can sustain and an extremely stressful experience for nurses. Comfort is needed throughout life, especially when one is suffering. Morse (1) describes comfort as an integral part of nursing, while other researchers use the term consolation. Norberg, Bergsten \& Lundman (2) described consolation as occurring when openness, presence and availability create trust. In a trusting relationship suffering can be revealed and shared in a reciprocal presence, i.e. in communion and experience of meaning can emerge. The concepts comfort and consolation are partly overlapping and sometimes used interchangeably (3). As the concept comfort can mean different things (4), it is important to understand the concrete needs for comfort of the individual person who is suffering.

Those who suffer can use self-comforting or self soothing strategies, such as taking time for oneself, and focusing on immediate needs $(5,6)$. According to Horton (7) the need to self-comfort is life-long.

\section{Comfort for comforters in pediatric palliative care}

The World Health Organization (8) describes palliative care for children as the active total care of the child's body, mind and spirit, and also involves giving support to the child's family. Children living with and dying from a life-threatening disease and their families suffer. As a child's disease and death often affect many persons, the child and his/her parents, siblings and the extended family need comfort (9). Family members often play a vital role in palliative care, both at home and in hospital, and their suffering can be a multidimensional experience of pain, sorrow, fear and vulnerability (10). Illness and death impact on how relationships are maintained within and outside a family $(11,12)$.

The death of a child is a tragic event for all involved, especially parents (12). In pediatric palliative care the focus is on providing palliation and comfort for the child and the child's family (9). Studies show that parents of children with life-threatening diseases valued continuity in the care of their child, a nurse who was there from beginning to end, showing compassion and performing small acts of kindness $(11,13)$. Nurses, who developed a close relationship with parents and turned their attention to the whole family, comforted parents. Parents were also relieved through practical help, kindness and thoughtfulness from their social network (14). Parents of children treated for cancer spoke about the comfort they received from other families and caregivers on the ward (15). The willingness of others to listen and be present can be comforting. The sense of being connected with others can give hope, and is in itself a deep source of meaning (16).

Nurses caring for a dying child can find it emotionally demanding to witness the child's and the child's parents' suffering and can play a crucial role in comforting children and their parents $(17,18)$. Nurses who had been deeply involved in the care of a dying child, could become like "family", through creating trust and being at the family's side (19). Papadatou, Bellali, Papazoglou \& Petraki (20) found that nurses felt helpless and powerless when they could not relieve the child's suffering. When a child died, nurses who had cared for the child felt the loss of a personal bond developed with the child, and they grieved over treatment that did not help (21).

Those who provide comfort, i.e. the comforters, thus need comfort, yet little is known about who and what comforts comforters. In the current study, we present parts of the analysed interviews with one dying boy's mother and his nurse, where they spontaneously spoke of how they and other persons in the network surrounding the dying boy were comforted. The child was in active treatment when he relapsed, the disease progressed rapidly creating great demands on both him and his family. To live under the extreme threat of losing one's child and how it affects parents, siblings and others close to the family and their need for comfort is sparsely documented in nursing research. Therefore, the aim of this study was to investigate how one dying child's mother and nurse described how they and other comforters of the child were comforted.

\section{Ethical considerations}

The participants, one mother and one nurse, were given written and oral information about the study. The mother received information from a nurse on the ward when the child was admitted to hospital, and later from the first author $(\mathrm{C} \AA \mathrm{B})$. When the mother accepted to participate, she and $\mathrm{CA} B$ informed the child about the study and he consented to participate. The mother and the siblings gave their consent to use the drawings they made. As the child mentioned the nurse as an important comforter, she was informed about the study and invited to participate, which she accepted. The mother, the child and the nurse were informed that they were free to withdraw from the study at any time before the data analysis without stating a reason. They were assured of confidentiality and anonymous presentation of the findings. 
The father declined participation. The Ethics Committee, Medical Faculty, Umeå University, Sweden, approved the study (05-017M).

\section{Methods}

Procedure and data collection

In 2005-2006 a study about the comforting of children undergoing cancer treatment was carried out at a pediatric oncology ward in northern Sweden (14). A 9 year old boy relapsed and CÅB met regularly with him and his family and made field notes at the hospital (22). In the current study, we present analysis of parts of the interviews with the boy's mother and his nurse.

While the child was receiving treatment and care until he died $\mathrm{C} \AA \mathrm{B}$ met with his mother 10 times during 7 months. They kept on conversation about what was going on in the family. The mother and the child's nurse were interviewed once about what they experienced and observed comforted the child at the hospital ward. To extract further details follow-up questions as; "What do you mean?", "Please, tell me more" were asked. During these interviews they also spontaneously talked about the comforting social networks that existed around the child and themselves. The interviews lasted 120 minutes and 80 minutes respectively. Mother gave us drawings that the child's siblings had made and explained that they gave us their permission to use them.

\section{Analysis}

\section{Content analysis}

A content analysis was performed (23). The interviews with the mother and nurse were analyzed separately. First they were read with focus on the boy. Then they were read through again to gain a sense of what the interviewees said about how comforters of the boy were comforted. Each interview text was divided into meaning units, which were then condensed, compared and coded. The coded meanings units were sorted into groups, compared and abstracted and according to similarities and differences 10 themes were constructed.

\section{Constructing a sociogram}

In order to illustrate a picture of who and what the mother and the nurse mentioned as comforting whom in the interviews, a sociogram was outlined that includes persons and activities mentioned as comforting (Figure 1) (cf. 24).

\section{FINDINGS}

Themes concerning who and what comforted the comforters are first presented and illustrated with quotations from interviews. Then the sociogram (Figure 1) is shown.

\section{Mother's accounts of how she was comforted \\ Experiencing a close and reciprocal relationship with the child}

The mother found comfort from experiencing a close and reciprocal relationship with her son and she explained how: "This has created a strong feeling of reciprocity, and extremely close relationship and it binds us strongly to one another and I understand that it is important". She felt comforted by being close to her son and from being told by him that she was a very important person for him. He said he wanted to be with her and that he never wanted her to die. Knowing that death was impending, the mother found comfort in being close to him and comforting him. The mother found comfort in experiencing her child feeling better for a moment, in hearing him laugh, and seeing him play in the midst of severe illness.

The mother found comfort in being in her own home, where she experienced peace and quiet, in the normal everydayness, surrounded by family members, and the atmosphere of home. Equally important was that she could help her son to be at home where he felt safe and comforted and received palliative care. The mother gained comfort because she knew how much he longed for home as: "the security of his home supported him the whole way despite the fact that he felt how very ill he was".
Staying by the child's side both at the hospital and at home comforted the mother. Performing basic and advanced nursing care and learning about treatment, meant she was involved and could provide him with comfort and ensure his safety. She found comfort in watching over her child, in being there and staying close to him.

\section{Sharing responsibility and feelings with her family}

The mother derived comfort from sharing the care responsibility with her husband. They shared the time with the child at the hospital and time and responsibility for taking care of siblings and doing homework. "From the beginning, we were here two days each and then we changed .. it was both to handle it myself and to be with him." When the mother was tired or sad, her husband relieved her by providing help or taking full responsibility for a while. Sharing the responsibility of caring for their child, as well as the feelings of joy and sadness eased the burden and made it easier for the mother to cope with all hardships. "It was extremely tough ... but we got to be with him so much time both."

The mother derived comfort from experiencing the siblings' thoughtfulness when taking care of their little brother. She felt happy when she observed them playing with him and taking care of him, and she noticed that his well-being improved. She said: "After the biopsy, he went as a hook, but they (the siblings) tricked him laugh." The siblings participated in the care at home: "They ruled the wheelchair, carried him, fetched stuff he needed, and was playing with him."

\section{Experiencing thoughtfulness and help from the nurse, extended family and others close to the family}

The mother wanted to be involved in discussions and decisions about the care and treatment of her son. She found comfort from sharing worries and feeling staff's understanding and said: "I'll meet with the nurse and the doctor today, I asked to do it".

The mother derived comfort from thoughtfulness and help from the extended family. They helped by taking care of siblings and by doing practical work at home. The comfort also included a relative's help with blood tests and nursing tasks. The boy's little cousin was very worried and asked her parents "to take her to the hospital" because she wanted to visit the boy. Mother said that "he was very sick that day, really bad, but at home, they have played very much". She played with him and stayed by his side even during his last days of life.

The attention from friends and others close to the family, in letters and greetings to the child and the family, and the thoughtfulness they showed comforted the mother. She understood others were thinking about them and cared about them.

\section{Finding ways to comfort herself}

The mother's situation was devastating. She felt comforted and found new strength when she had time and space for herself: "I really try and I see to it that I have my own time, now I am going out for a walk, I have no mobile phone with me, I do that." She used the time to reflect on what was happening to her child, to herself, and to the family. She was afraid and sad, grieving over her dying child, but said in some ways she had to manage the demanding situation.

\section{The mother's accounts of how siblings were comforted Talking and taking care of each other}

The mother said that the child's siblings were informed about their little brother's disease and after his relapse they knew he was dying. They found comfort in talking about it in an open and trustful way with one another and with their little brother: "We talked about it and we were very open with all the children. We told them what was going to happen and let them ask questions." They found comfort in being close to their brother, playing and doing things with him.

\section{Living everyday life}

The mother explained that the siblings were comforted by their everyday life going on as usual. They found comfort in the whole family spending time together at home and in having some part of their everyday life despite the circumstances. For the siblings, another source 
of comfort was school. "Their lives are at school and it was very important that they should continue to go, it worked well". The siblings found comfort in being with their friends and in daily activities, music and through expressing their feelings by drawing (Drawings 1 and 2). The mother commented on the siblings' drawings and said: "The siblings expressed it (their feelings) by drawing pictures. Their pictures of hospital corridors and the portrait of the little brother are examples of this. They illustrate in theme, colour and intensity what they feel. Maybe you can't describe the feeling in words but art is descriptive".

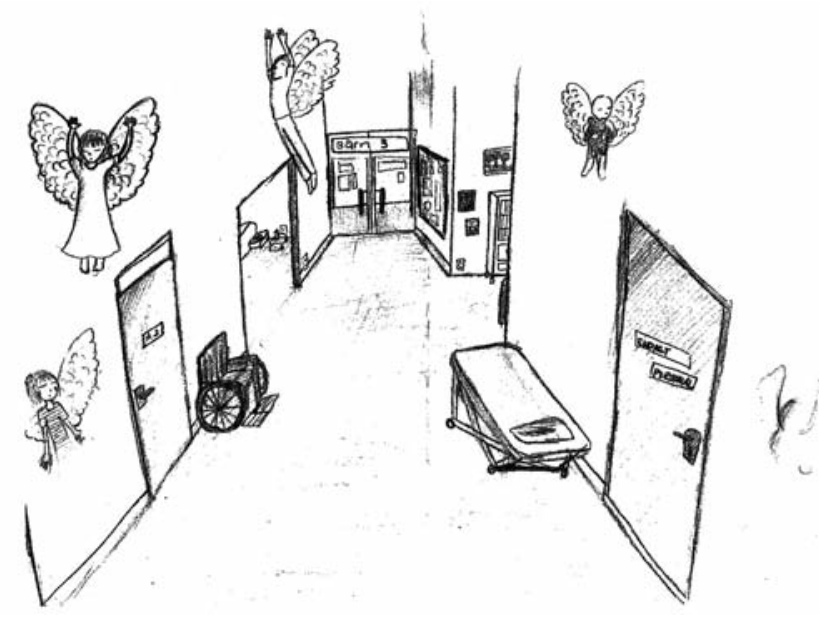

Drawing 1

The child's 13 year old sibling drew the hospital ward where the little brother was cared. Neither children nor staff can be seen, but there are angels flying around. The sibling was thinking that the children on the ward died and became angels.

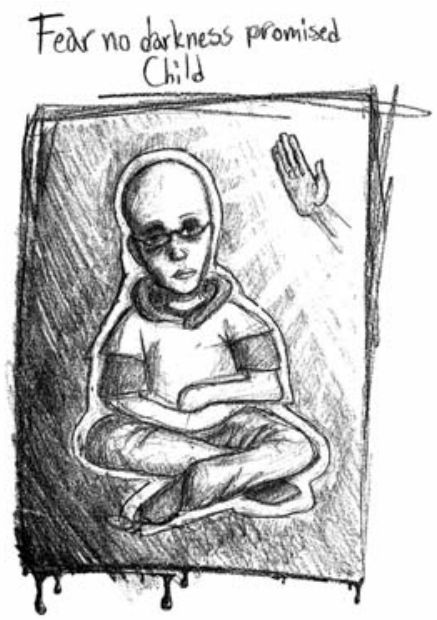

Drawing 2

Another sibling, 15 year old, drew a portrait of the little brother before he died. The text "Fear no darkness promised child" is the title of a tune the family listened to during the illness trajectory and afterwards.

\section{The nurse's accounts of how she was comforted}

\section{Making a difference to the child}

The nurse found comfort in experiencing the child's trust when she was caring for him; this trust was gradually built up from the start of the treatment. The child watched her and sized her up without talking. She persisted in talking to him, got to know him and found out that he trusted her. "That was what happened, we found each other." This meant that she wanted, even more, to do whatever she could to help him. The nurse derived comfort from seeing him have less pain, as it meant she was able to do something to make him feel better. She cared for him whenever she was on duty and they learned to know each other. She said "it took time to learn to know him and read him," but after some time she was able "to see in his eyes what he wanted." She wanted "to

see the child behind the illness" and explained that "he has taught me so much" about nursing and that it was rewarding to care for him. The nurse felt comforted when perceiving that her care made a difference through managing to learn how to ease the symptoms.

\section{Sharing hardships with colleagues and a relative}

The nurse derived comfort from colleagues' kindness and thoughtfulness. "They kept on asking how the child was and how I was." It made her work easier to be able to talk and share the hardships with her colleagues who knew the difficulties. She also found comfort through supervision. The friendly atmosphere on the ward eased and strengthened her. The ward as a place where there was life and joy although many children were very ill. Another source of comfort was a relative close to her who comforted her by listening to her and embracing her. Without disclosing any information about the child, she talked about nursing in a very difficult situation.

\section{The nurse's accounts of comforting parents} Involving and working closely with parents

When the nurse was caring for the child she tried to comfort his parents. She said: "The heavy workload on the ward hampered their contact", but she always tried to help. She asked how the parents were and talked to them, informed them about procedures and treatment and tried to facilitate the care of the child by being one step ahead. She involved the parents in the care and worked closely with them. When the child did not want to talk to her or, refused to answer questions, she talked to his parents, entering into a kind of team work to do everything that was best for the child

\section{Parents on the ward were perceived to comfort each other}

The nurse said that parents of other children with cancer comforted each other when they spent time on the ward by sharing experiences: "They may become friends for life. Persons who've been through the same sort of thing, who've been there, and who know what it's about, they can comfort and give each other support". When the parents were admitted to the ward they were invited to a support group, where they could share experiences about their children's diseases, treatments and also share emotional reactions.

Figure 1. The comforting social networks

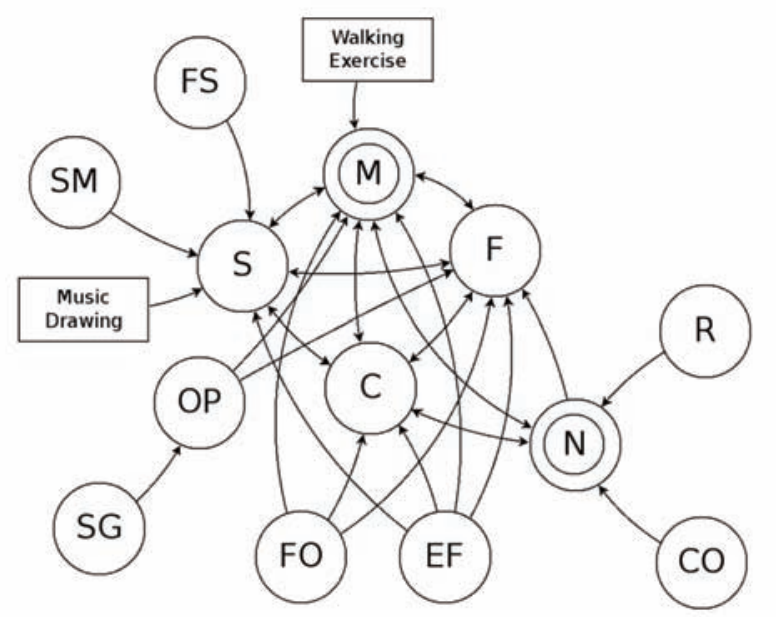

\section{Abbreviations}

\section{$\mathrm{C}$ - child}

$\mathrm{M}$ - mother (interviewee)

$\mathrm{F}$ - father

$\mathrm{N}$ - nurse (interviewee)

$\mathrm{EF}$ - extended family

FO - friends and others close to the family FS - friends of siblings

$\mathrm{OP}$ - other parents of sick children

One-way or two-way arrows show who comforted whom. 


\section{Discussion}

The aim of this study was to describe how comforters of one dying child were comforted, described by the child's mother and nurse. The findings provide a picture of interacting comforting networks.

In this comforting network, reciprocity appeared essential. So for example, the ill and eventually dying child was in need of comfort but also provided comfort for his family and nurse. The mother found comfort in being reassured by the child that she managed to comfort him by being close and actively caring for him, siblings in being able to make the child laugh and play and the nurse in perceiving that she made a difference through managing to learn how to ease the symptoms. Comfort was also visible between the mother, the father and among the siblings. Although we could not interview the father as he declined participation, in the mother's and nurse's accounts the father played a significant role; needing comfort as well as comforting his family. The parents tried to spend equal amount of time with their child as with siblings at home and at times one parent took full responsibility, so that the other parent could rest for a while, and have time to recover. Together they took care of their children and they literally carried each other. The siblings found comfort in mutual concern for one another, involving the child in their playing, drawing and everyday activities. The everyday normality conquered the sadness and sorrow for a while and the reciprocal concern for one another's wellbeing comforted all involved as no one was left outside. Zelcer, Cataudella, Cairney \& Bannister (25) reported maintaining normality as important for the whole family when a child is dying. Thus, to summarize, finding comfort for the sufferer means bringing comfort also to the comforter.

The findings show that the mother shared feelings with her family and the nurse. Reciprocity implies sharing. In our findings sharing has a special quality of sharing without words on the level described as moments of communion. Lindström, Lindholm \& Zetterlund (26) described caring communion as characterized by intensity and vitality, warmth, closeness, rest, respect, honesty and tolerance, requiring a meeting in time and space and absolute presence. The mother in our study was able, from time to time, to share the painful experience with family members. There was often open, honest and ongoing communication within the family in which all the siblings were allowed to ask questions and get information no matter how painful about the progression of the disease. They all knew what was going to happen and sharing feelings, beyond words brought them some comfort which might have been unique for this family.

Our findings show that parents found comfort by sharing their feelings with other parents on the ward. D'Agostino, Berlin-Romalis, Jovcevska \& Barrera (27) reported similar observations. The mother found comfort from sharing worries not only with other parents but also in being involved in discussions about care with nurses who passed on their knowledge to the family, making them part of caring. It seems reasonable that the nurse found comfort on a personal basis (not professional) when sharing her feelings with a relative.

Not only did the family need comfort, our findings show that the nurse also had a comforting network at work and in her private life. Being listened to and sharing sorrow with other professionals on the ward helped her to be present for the child and his family, and find ways to make a positive difference for the whole family. Develop close relationships with parents and playing a role in alleviating distress has been described as rewarding (28). Being involved in a tragic situation can be a burden and calls for comfort. Sharing with those who were able to listen was often mentioned as a way of finding self-comfort and of being reconciled to the inevitable suffering as shown by Dahlqvist, Söderberg \& Norberg (5).

When faced with illness and death the parents found comfort in being able to lean on each other and share the responsibility regarding practical issues. The siblings showed responsibility and involved themselves in the care of their sick sibling. Their thoughtfulness and concern comforted both the mother and the child when he was dying. Extended family and friends and others close to the family showed concern by offering practical help; this comforted the mother. The child's impending death made great demands not only on parents but also on the nurse who felt a professional and personal responsibility to comfort both the child and his family. Sharing hardships with colleagues, family and friends, and seeking support from a relative, talking to them and knowing that they stood at her side, meant that the responsibility became bearable. As the nurse is committed to the confidentiality of her patients, she of course can only talk in general terms about her hardship with people not working at her ward.

\section{Methodological consideration}

As mentioned before, we present parts of the analysed interviews with the boy's mother and his nurse, where they spontaneously spoke of how they and other persons in the social networks surrounding the dying boy were comforted. Our intention was not to interview the mother and the nurse about their experiences of comfort and comfort deriving from social networks. The interviews focused on the dying child's experiences of comfort and we could not follow up persons mentioned in the social networks with additional interviews. Data were collected through the eyes of the mother and the nurse, reflecting their perspectives, which may have influenced the findings. It is possible that the father and siblings would have told other stories. The child was in active treatment when he relapsed, the disease progressed rapidly creating great demands on both him and his family. As comfort is rarely described with reference to social networks we regard our data as interesting

\section{Implications for pediatric nursing}

Our findings may be transferable to other contexts in which dying children are cared for. Illness and suffering are shared experiences in a family. Comfort is very difficult to achieve. It seems important to facilitate the family's involvement in caring for the child. Comfort can often be enhanced through involvement of existing social networks by engaging them in helping the family. Opportunities for nurses to share experiences with colleagues are important.

\section{Conclusion}

In a pediatric context, when a child is dying the suffering is described as a devastating experience for everyone concerned. It is the child who suffers most and the child's family who carries the heaviest burden but they are still able to give a lot of comfort to each other if they are surrounded by social networks where reciprocity, sharing suffering and shouldering each other's responsibilities ease the suffering and bring comfort. Family members and those in comforting social networks have different ways of and resources for providing comfort but taken together comforting networks act as a protective system each and all of the family members.

\section{Acknowledgement}

The authors would like to thank the mother and nurse who participated in the study and so generously shared their experiences. This study was funded by grants from the Swedish Childhood Cancer Foundation (LON 06/14).

Accepted for publication 2.05.2014

Corresponding author Charlotte Ångström-Brännström, R.N.T, Ph.D., Assistant Professor, Faculty of Medicine, Department of Nursing, Umeå University, SE 90187 Umeå,

E-mail: charlotte.angstrom@nurs.umu.se

Vera Dahlqvist, R.N.T., Ph.D., Assistant Professor, Ersta Sköndal University College, P. O. Box 111 89, SE 10061 Stockholm. Gunilla Strandberg, R.N.T, Ph.D., Professor, Faculty of Medicine, Department of Nursing, Umeå University, SE 93187 Skellefteå, Sweden

Astrid Norberg, R.N., Ph.D., Professor Emerita, Faculty of Medicine, Department of Nursing, Umeå University, SE 90187 Umeå and Palliative Research Centre, Ersta Sköndal University College, P.O. Box 111 89, SE 10061 Stockholm. 


\section{References}

1. Morse JM. On comfort and comforting. American Journal of Nursing. 2000;100(9):34-38.

2. Norberg A, Bergsten M, Lundman B. A model of consolation. Nursing Ethics. 2001;8(6):544-553.

3. Comfort - definition, etymology and usage. http://www.finedictionary.com/comfort.html Accessed January 27, 2014.

4. Kolcaba KY, Kolcaba RJ. An analysis of the concept of comfort. Journal of Advanced Nursing. 1991;16(11):1301-1310.

5. Dahlqvist V, Söderberg A, Norberg A. Dealing with stress: patterns of self-comfort among healthcare students. Nurse Education Today. 2008;28(4):476-484

6. Wright, J. Self-soothing - A recursive intraphysic and relational process: the contribution of the Bowen theory to the process of self-soothing. Australian and New Zeeland Journal of Family Therapy. 2009;30(1):29-41.

7. Horton P C. Self-comforting strategies used by adolescents. Bulletin of Menniger Clinic. 2002;66(3)259-272.

8. World Health Organization. WHO definition of palliative care. http://www.who.int/cancer/palliative/definition/en/Accessed November 24, 2013.

9. Knapp C S, Contro N. Family support services in pediatric palliative care. American Journal of Hospice \& Palliative Medicine. 2009;26(6):476-482.

10. Mehta A, Cohen R S, Chan L S. Palliative care: a need for a family systems approach. Palliative and Supportive Care. 2009;7(2):235-243.

11. Monterosso L, Kristjanson L J. Supportive care and palliative needs of families of children who die from cancer: an Australian study. Palliative Medicine. 2008;22(1):59-69.

12. Woodgate R L. The importance of being there: perspectives of social support by adolescents with cancer. Journal of Pediatric Oncology Nursing. 2006; 23(3):122-134.

13. Heller K, Solomon M. Continuity of care and caring: what matters to parents of children with life-threatening conditions. Journal of Pediatric Nursing. 2005;20(5):335-346.

14. Ångström-Brännström C, Norberg A, Strandberg G, Söderberg A, Dahlqvist V. Parents' experiences of what is comforting them when their child is suffering from cancer. Journal of Pediatric Oncology Nursing. 2010;27(5): 266-275.

15. McGrath P B, Paton M A, Huff N. Beginning treatment for paediatric acute myeloid leukaemia: diagnosis and the early hospital experience. Scandinavian Journal of Caring Sciences. 2004;18(4):358-367.
16. Romanoff B D, Thompson B E. Meaning construction in palliative care: the use of narrative, ritual and the expressive arts. American Journal of Hospice \& Palliative Medicine. 2006; 23(4):309-316.

17. Costello J, Trinder-Brook A. Children's nurses' experiences of caring for dying children in hospital. Paediatric Nursing. 2000;12(6):28-32.

18. Roche-Fahy V, Dowling M. Providing comfort to patients in their palliative care trajectory: experiences of female nurses working in a acute setting. International Journal of Palliative Nursing. 2009;15(3):134-141.

19. Meert K L, Briller S H, Schim S M, Thurston C, Kabel A. Examining the needs of bereaved parents in the pediatric intensive care unit: a qualitative study. Death Studies. 2009;33(8):712-740.

20. Papadatou D, Bellali T, Papazoglou I, Petraki D. Greek nurse' and physicians' grief as a result of caring for children dying of cancer. Pediatric Nursing. 2002;28(4):345-353.

21. Lieben S, Papadatou D, Wolfe J. Paediatric palliative care: challenges and emerging ideas. The Lancet. 2008;371(9615):852-864.

22. Ångström-Brännström C, Dahlqvist V, Norberg A. Victor and the dragon - a young child's experiences of discomfort and comfort, from diagnosis to death. Journal of Hospice and Palliative Nursing. 2014 (in press).

23. Graneheim U H, Lundman B. Qualitative content analysis in nursing research: concepts, procedures and measures to achieve trustworthiness. Nurse Education Today. 2004;24(2):105-112.

24. Phaneuf $M$. The sociogram - a complementary tool to the genogram and a means of enriching the interview.

http://www.infiressources.ca/fer/Depotdocument_anglais/The_sociogram.pdf Accessed November 24, 2013.

25. Zelcer S, Cataudella D, Cairney E, Bannister S. Palliative care of children with brain tumors. Archives of Pediatrics \& Adolescent Medicine. 2010;164(3):225-230.

26. Lindström U, Lindholm L, Zetterlund J E. Theory of caritative caring. (Chapter 11, pp 191- 207). In Marriner Tomey A, Alligood M R. Nursing theorists and their work. 6th ed. Mosby: St. Louis. 2006.

27. D'Agostino N, Berlin-Romalis D, Jovcevska V, Barrera M. Bereaved parents perspectives on their needs. Palliative and Supportive Care. 2008;6(1):33-41.

28. Klassen A, Gulati S, Dix D. Health care providers' perspectives about working with parents of children with cancer: a qualitative study. Journal of Pediatric Oncology Nursing. 2012;29(2):92-97. 